\title{
Critical Thinking and Community of Inquiry within Professional Organizations in the Developing World
}

Journal of Human Values

23(I) 13-20

(C) 2017 Management Centre for Human Values

SAGE Publications sagepub.in/home.nav

DOI: I0.I I77/097|6858|6673479 http://jhv.sagepub.com

๑SAGE

\section{Peter Paul E. Elicor'}

\begin{abstract}
In this article, I intend to underscore the importance of critical thinking in rendering invaluable positive contributions and impact within professional organizations in the developing world. I argue that critical thinking treated as a normative principle and balanced with a pragmatic orientation provides a rational framework for resolving conflicts that oftentimes ensue from the incoherence between Western-based organizational theories and the actual circumstances of a developing country. In order to optimize the benefits of critical thinking, I also argue that it should not be expected only among leaders and managers, but also and more importantly, among organizational members and associates. It is for this reason that I introduce Matthew Lipman's Community of Inquiry as a model for cultivating critical thinking within professional environments.
\end{abstract}

\section{Keywords}

Critical thinking, community of inquiry, Matthew Lipman, organizational values, organizational identity

\section{Introduction}

Gentry and Eckert (2016) observe that leaders in the twenty-first century face a multitude of challenges, encompassing both internal and external boundaries to remain highly competitive and effective. They must work 'across cultural boundaries and alongside others who, at times, are very different from them and have different ways of getting work completed' (Gentry et al., 2016, p. 3). Due to the rapid changes brought about by globalization and economic liberalization across developing countries, it is imperative to see the needed reforms in the mentality and professional arsenal of leaders, administrators and managers. Among the most important factors that contribute to the growth of an organization to become a robust and successful global entity is a set of effective managerial values and skills. Developing managerial values, which include prioritization, strategic thinking and wise decision making, is greatly needed to wade through the obstacles within a complex globalized environment. It must be emphasized,

' Department of Philosophy, Ateneo de Davao University, Davao City, Philippines.

Corresponding author:

Peter Paul E. Elicor, IDepartment of Philosophy, Ateneo de Davao University, Davao City, Philippines.

E-mail: ppeelicor@addu.edu.ph 
Journal of Human Values 23(I)

however, that there is hardly a perfect set of managerial values that would easily address such challenges. Critical thinking, which is a normative value, may prove to be useful in this area.

While heaps of researches on organizational literature and managerial techniques abound, there has been very few researches focusing on the advantages of critical thinking and reflection. In fact, in maintaining organizational identity, Brown and Starkey (2000, p. 103) note that 'learning to promote critical reflection upon organizational identity is a crucial but undertheorized management task'. The problem is that in most organizational literature and management techniques, critical thinking is often immediately subsumed under the general set of mental skills that are essential for any organizational leader. Its corollary values, such as reliance on a sound logical criteria, ability for self-correction and sensitivity to the context, are incorporated within good managerial skillsets without a focused study on how these values actually intersect. That explicit links between organizational theory and the values of critical thinking are few and far between is probably due to the perception that critical thinking is a 'given' value that needs no elaboration. This is a gap that the present study attempts to address.

It may be well to note that the term 'critical thinking' is often used in the context of education. Schools must be centres of freedom and dialogue. This means that institutions should be able to provide an environment that is conducive to critical questions. As an educational ideal, it is hoped to enable students to think properly on the basis of certain logical criteria. However, critical thinking is also a necessary skill that benefits those who apply it beyond the four corners of the classroom since the cultivation of reason and adherence to logical principles are universal ideals that do not discriminate context. If it is an academic model within schools, it may therefore also be a normative ideal within professional organizations.

Within and among school administrators and members, Whetten (1984, p. 40) recalls his experience as a member of a business school faculty from which he realized that 'many business managers could learn a great deal about organizational attributes from their counterparts in the academe'. In what he calls 'catalytic' leadership style, several administrative attributes are actually very relevant and applicable in any organizational setting. In contrast to a charismatic leader who utilizes administrative powers to warrant members' obedience, a catalytic leader puts emphasis on the values of team work, accountability and effective communication. These attributes are actually principles that intersect within the internal ordinates of critical thinking. It is instructive to pay close attention to the study of academic administration as contributory to the domain of management in general.

This article will proceed in three steps. First, I will discuss the concept of critical thinking. Second, I will argue that developing critical thinking as a normative principle is an essential managerial tool in developing countries whereby Western-centric organizational models are at times deemed inappropriate or irrelevant due to the differences in local values, culture and socio-political arrangements. Lastly, I will propose that Matthew Lipman's Community of Inquiry provides necessary insights on how to govern an organization, empower business employees and partners, and ultimately build an organizational identity that is founded on reason.

\section{Matthew Lipman's Critical Thinking}

Critical thinking, according to Matthew Lipman (2003, p. 212), is thinking that 'facilitates judgment because it relies on criteria, is self-correcting, and is sensitive to context'. As a general rule, reliance on a sound logical criterion is vital in arriving at any form of judgement. This precludes judgements that are based simply on impulse, emotions and groundless claims. With a clear and unwavering awareness of the importance of reasonable standards, one would hardly fall into conclusions that are whimsical, 
inappropriate and irrelevant. Logical principles validly boost the process of thinking and by means of logical criteria, decisions or judgements that are engendered by such process can likewise be validly defended. This goes to say that critical thinking is not an end in itself. It is aimed at helping the mind to form reasonable conclusions and proper judgements on whatever problem that is under investigation.

One may ask, "whenever a person thinks, is s/he not already thinking critically, that is, thinking with implicit criteria?' Critical thinking is reflexive thinking. It pertains to the ability to think not only about what one thinks but also why and how one thinks in a particular manner, and in a particular context. In other words, it is the ability to reflect and evaluate one's processes of thinking against universal logical criteria. And to do such kind of thinking while thinking is not a simple task. It is a form of meta-cognition that requires a sharp mental attention of quickly bringing into a higher abstraction what one just thought about or is actually thinking. Lipman observes that 'we can think about our own thinking, but we can do so in a way that is still quite uncritical' (2003, p. 218). One may, for instance, easily justify the mental errors committed, deliberately or not. Hence, the kind of thinking that is not yet capable of discovering and rectifying its own weaknesses is still far from being critical. One has to always recognize the fallibility of one's thought processes and outputs in order to avoid making wrong assumptions and judgements. This explains why critical thinking lies at the opposite of dogma and indoctrination. Since it is selfcorrecting, it avoids thinking in absolutes.

Though logical criteria are, most of the time, universal and objective, critical thinking is simultaneously sensitive to the context in which the criteria are to be applied. This balances critical thinking's appeal to generalizations and universal logical principles (which are in themselves dependable) and its sensitivity towards the actual distinctiveness of a given circumstance. In other words, critical thinking does not regard rationality merely as an abstract template ready to be imposed on any circumstance disregarding some crucial local conditions. Hence, it must be emphasized that critical thinking is not just mere reasoning; rather, it is thinking that is appropriately applied against the background of a specific situation. It does not only refer to the process of thinking but to the developing of an output. The minimal output is a context-appropriate judgement, while its maximal output is the application of such judgement into concrete action. Lipman cites Charles Pierce's illustration in defining his pragmatic principle, which in this context, highlights the importance of balancing the normative character of critical thinking with a pragmatic orientation. The significance of any concept is said to be found in the 'scratch test'. 'Diamonds are harder than glass if diamonds scratch glass but glass cannot scratch diamonds' (Lipman, 2003, p. 207). This means to say that any form of abstract concept, process or judgement is devoid of any significance without practical and tangible results. To look for the right judgement that best fits a very unique concrete situation, which in turn produces practical result, is the perfect example of critical thinking at work.

In what follows, I will argue that critical thinking as a normative ideal can actually provide a rational framework for resolving conflicts that oftentimes ensue from the incoherence between Western-based organizational theories to the actual circumstances of a developing country.

\section{Critical Thinking as a Normative Ideal}

Kiggundu, Jørgensen and Hafsi (1983) undertook an extensive research utilizing academic articles (written between 1956 and 1981) that studied the application of Western-centric organizational theories and administrative techniques in developing countries. The results show that the 'weak fit' (i.e., cluster of articles that emphasized the need for major modifications before any Western administrative theory or set of techniques can be adequately applied in developing countries) outweighs the 'strong fit', which, 
Journal of Human Values 23(I)

on the contrary, stressed that management techniques or organizational theory can actually be transferred from the industrialized to developing countries without any modifications. This study shows that there are several factors that cause the inapplicability, if not irrelevance, of Western-based theories in the traditional landscape of developing countries. Some of these factors include culture, economic and political/institutional systems. Though there are certain elements that are readily transferrable and implementable from the highly developed countries to those that are still developing; these, however, are limited to the 'core technology', such as basic organizational structure, budgeting and the use of computers. These may be applied without modifications under certain conditions where there is not much need of any direct and extensive interaction with the environment. Accordingly, cultural differences, people's value orientation and socio-political arrangements are crucial factors to be considered before a theory is concretized in developing countries. The researchers note that 'each time the environment is involved, the theory developed for western settings does not apply, because it assumes contingencies that may not be valid for developing countries' (Kiggundu et al., 1983, p. 81). Another study that highlights the crucial impact of cultural differences and practices that cause inconsistencies in terms of organizational ethics is a research conducted by Al-Khatib, Mohammed and Vitell (2004). According to them, the context of the 'Gulf culture' which is built upon values of 'collectivism, passiveness and submission to authority' and a 'sense of entitlement to the job' make it difficult, if not impossible, for organizational members to establish an ethical framework that could actually improve the quality of their performance and standard of excellence (Al-Khatib et al., 2004, p. 318).

In this regard, critical thinking, especially its emphasis on a pragmatic direction becomes ever more relevant. Developing countries can only maximize Western-based organizational models once they go through a critical deliberation of their applicability and appropriateness using relevant criteria. This is when organizational leaders and managers are expected to exercise their critical thinking skills. One of the purposes of managerial positions is to establish an integrated organizational identity (an answer to the question: who are we as an organization?) that is not just imposed directly from a foreign model, but an identity that each of the actual members of the group can fully understand and deliberately incorporate within their own individual values. On this note, Voss, Cable and Voss (2006, p. 743) argue that 'when leaders are forced to negotiate identity, the process enhances their ability to monitor and recognize environmental changes and creates flexibility to adapt'. Maintaining a sense of organizational identity practically involves a process of constant adaptation, rethinking and renegotiation against the backdrop of global shifts in economy, culture and politics. However, such capability requires a 'catalytic' leader who values critical thinking while at the same time fosters effective communication and accountability within and among the organization's members. It is for this reason that the outcome of critical reflection upon the nature of identity is 'a self-reflexive and wise organization, secure in its ability to negotiate identity change as part of its future strategic development' (Brown \& Starkey, 2000, p. 103). At this point, a question may be raised concerning the 'Western character' of critical thinking which, as shown above, may not necessarily make a 'strong fit' within organizations in developing countries. While it is true that critical thinking obviously has Western origins, the utilization of rational principles, rules of logic, employment of criteria are, on the other hand, universal human capacities that do not discriminate culture and epoch. Lipman (2003, p. 34) cites John Dewey who argued that the practice of 'inquiry', which by association includes critical thinking, 'can be traced back to its origins in everyday problem solving'.

Meanwhile, when confronted with a problem that concerns, for instance, the identity of an organization, Robert Ennis's six essential elements that constitute successful result of critical thinking may be used as a model. These elements can be conveniently recalled via the acronym FRISCO which means: Focus: identify the focus or central concern; $\underline{R}$ eason: identify and judge the acceptability of the reasons; 


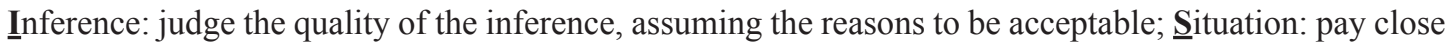

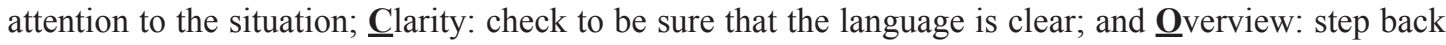
and look at it all as a whole (Ennis, 1991, p. 20). In the areas of trouble shooting, problem solving and decision making, these essential elements are very much called for. What is demanded from a leader are not simply reasons, but good reasons in choosing the right methodology and employing it correctly in order to arrive at a rational decision. Lipman asserts that professionals, and by extension, including organizational leaders, 'recognized that their standings in the professions were based not on the thoroughness of their knowledge but on their judgment: the facility with which they could put their knowledge to appropriate use' (Lipman, 2003, p. 207). By putting their acquired knowledge and training to proper use, they usually need to appeal to criteria, aided with empirical evidence via research or through the usual modes of inductive or deductive reasoning that necessarily narrow down several options to the most appropriate solution. It may be well to note that most defects in reasoning stem from flawed thought processes that most of the time render one's thoughts or decisions inept, biased and inaccurate. In traditional logic, these are called informal fallacies which refer to the several forms of erroneous thinking that are normally caused by misconceptions of one's implicit assumptions, misapplication of language or simply by a lack of clarity in one's cognitive methods. Among the many forms of informal fallacies are attack on a person rather than an argument (argumentum ad hominem), ambiguity, improper appeal to authority, appeal to fear, faulty argument from analogy, dubious assumption, jumping to conclusions and post hoc ergo propter hoc, (after this, therefore, because of this) to name a few. The result of these fallacies obviously affects the precision, consistency, relevance and sufficiency of anyone's mental ability (cf. Lipman, 2003, p. 236). This explains why in the workplace, or in any professional organization, the normativity of good thinking is not a luxury but an imperative. Schmidt and Hunter (1998, p. 262) note, for instance, that in 'hiring employees without previous experience in the job, the most valid predictor of future performance and learning is general mental ability'. This means that one of the determinants of the successful performance of an employee - which will greatly impact the organization as a whole - is the ability to reason well. On this subject, Chartrand, Ishikawa and Flanigan (2013, p. 3) observe that

people who score well on critical thinking assessment are also rated by their supervisors as having: good analysis and problem-solving skills, good judgment and decision making, good overall job performance, the ability to evaluate the quality of information presented, creativity, job knowledge, and potential to move up within the organization.

Such mental regimen is not possible if one were merely to take theories as infallible patterns that have identical applicability in almost all situations.

It cannot be emphasized enough that critical thinking always entails a higher level of sensitivity to the uniqueness of a given context. As a normative principle, it always guides the process of deliberation and decision making. Its output, however, must be expected to vary from one context to another. Critical thinking, therefore, is not a stand-alone value but rather a skill that stands among other hosts of abilities and professional traits. By and large, critical thinking, alongside other managerial values and skills, is an indispensable trait that organizations must seek for among its leaders and associates. They are like 'building blocks' upon which effective management rests (Whetten \& Cameron, 2011, p. 8). Considering the challenges in economic liberalization, shifts in organizational identities, adaptation to the modern global working conditions, the cultivation of critical thinking, especially among developing countries, should form part of their entire managerial ethos.

In what follows, I will argue that to optimize the benefits of critical thinking, it should not be expected only among leaders and managers, but also and more importantly, among organizational members and associates. 
Journal of Human Values 23(I)

\section{Community of Inquiry within Organizations}

Lipman (2003, p. 97) proposes to use the concept of Community of Inquiry as an educational model that aims at inducing the members of an academic class to be reflective to engage in reflective reading, reflective questioning and reflective discussion. While it is true that the context where Lipman recommends such community to be employed is rather different from professional organizations, the values and principles that such community tries to uphold are nevertheless invaluable if applied within business enterprises or any organization that constitute professional individuals. A manager who may have the capacity for critical thinking can only do so much. If the employees are not empowered to think for themselves, collaborate and contribute for the growth of the company, all efforts to steer the group to its goals are useless. The assumption here is that organizations exist precisely because it is constituted by stakeholders who equally have rational claims to it. It is not enough to have one critical thinker. Critical thinking has to be shared among associates, no matter how diverse these members are. One can neither underestimate nor discredit the capacity of the members to bring effective change in a company. For instance, Glynn, Barr and Dacin (2000, p. 726) suggest that in developing organizational models, 'scholars need to incorporate more explicitly diversity per se as sources of strategic advantage, responses to situational pressures, and conceptions of identity in organizations'.

It is already a common phenomenon that due to the rapid changes in the work settings, employees are challenged to take on different roles with their corresponding responsibilities. As a result, all members in an organization are expected to adapt to the increasing professional demands brought about by the shifts in both micro- and macro-levels of professional environment. In this regard, critical thinking skills are expected not only among persons who assume high posts within an organization but also among its members. The capacity to think objectively is an imperative not only among administrators who hold positions of authority but also among the rank-and-file employees. In order to promote and integrate critical thinking within an organization, Ricci (2014, p. 68) suggests that leaders must create 'an awareness of the importance of critical thinking within each schedule of events, group meetings, planning, and project management coordination, analysis of financial reports, and organizational trends and projections'. This can be practically introduced by encouraging employees to raise questions which they think are relevant to the process and the outcomes of the matter being discussed via small group discussions, peer or group evaluations and consultations. As a result, the employees will be empowered to articulate their thoughts, clarify vague concepts, provide concrete examples, recognize assumptions, imagine different outcomes and ultimately draw conclusions. It is for this reason that Verbos, Gerard, Forshey, Harding, and Miller (2007, p. 24) contend that one of the factors that promote a positive ethical organization, which is marked by a sense of community, is the delegation of decision-making process 'at all levels of an organization: from executive planning and strategy formulation through to the day-to-day decisions of front line employees'.

Moreover, in speaking of a community of inquiry, Lipman notices the contrasting characteristic between conversation and dialogue. He explains, 'in contrasting conversation and dialogue we cannot help seeing in conversation a process in which the personal note is strong but the logical thread is weak, whereas in dialogue just the reverse is the case' (Lipman, 2003, p. 87). It is clear that one of the immediate aims of the community of inquiry is to encourage its members to transcend personal biases and prejudices in order to objectively perceive and evaluate the matters being discussed. Among the many ways to achieve this is to encourage each member to look at certain matters from different perspectives. Further, in a dialogue, 'disequilibrium is enforced in order to compel forward movement' (ibid., p. 87). Just as forward movement in the act of walking is made possible by constantly throwing one's self off balance, the community of inquiry moves forward by engaging in dialogue whereby arguments are 
constantly evaluated and even opposed by better arguments until a good judgement is collectively achieved and accepted. In particular, critical questions provide a 'stimulus and direction for critical thinking; they move us forward toward a continual, ongoing search for better opinions, decisions, or judgments' (Browne \& Keeley, 2007, p. 2).

The upshot of this process is the cultivation of the attitude of healthy criticism (and self-criticism). By encouraging constructive criticism within an organization, self-empowerment, humility and accountability are definitely fostered. In this regard, Paul and Elder (2006, p. 42) notice that critical thinkers 'share a common core of purposes in keeping with the values of critical thinking'. This is where awareness and good grasp of the organizational identity are called for. One does not arrive at anything if there is a lack of knowledge as to the purpose of what one upholds and shares with the others. Arriving at a destination is impossible if one does not know where s/he is currently at and what goals does s/he plan to achieve. That is why 'in order to determine the way forward for business and society in the twenty first century, [one] must first know where [one] stands' (Ferguson, 2011, p. 3). A thorough understanding of the organizational identity plus critical thinking definitely steer any business enterprise into the right direction. It cannot be emphasized enough that in an organization, it is essential that all members can clearly identify their personal values and the values that the company holds.

\section{Conclusion}

In this article, I have argued that critical thinking does not only work within academic institutions but may also be used as an essential tool for managing organizations in developing countries. In order to explore and illustrate this potential, I have drawn the meaning of critical thinking from Matthew Lipman and emphasized its reliance on criteria, self-correcting character and sensitivity to the context. Critical thinking is not just mere reasoning, but rather a process of thinking that involves a reflexive awareness of one's assumptions and criteria, a clear understanding of the elements that define a particular situation, and more importantly, a willingness to engage in a community for dialogue and deliberation, which altogether aim at developing an output, that is, practical solutions to certain organizational problems. It has a strong pragmatic orientation which makes it a normative ideal in dealing with problems that arise in an organization or any human collective. Hence, it is not simply a process of applying any theory at a given context, but more essentially, it is a process of critically evaluating the appropriateness of any concept, managerial technique or organizational practice that is sought to be appropriated in a particular setting.

Moreover, critical thinking does not only gain foothold within academic classrooms but also within bigger offices of professional organizations. Critical thinking as a normative principle is a powerful tool that contributes to the professional arsenal of any organization particularly in crucial decision making, trouble shooting and steering the company towards holistic organizational advancement that benefit not only the few but all its members. I have argued, further, that Western-based organizational models may be irrelevant and inappropriate for direct and immediate application in developing countries due to the varying circumstances in culture, society and politics. This makes critical thinking even more necessary as a managerial imperative in developing countries. In their specific contexts, organizational identity is best built from the 'bottom-up' which entails continuous critical evaluation of the organization's dynamic identity and constant adaptation to the environment. This is also where critical thinking's pragmatic characteristic allows for a higher sensitivity to concrete situations that may call for non-identical judgements and applications. 
Journal of Human Values 23(I)

Lastly, it is by expanding the possible scope of critical thinking - from classrooms to workplaces and other forms of professional environment - that we can begin to understand how an organization actually requires good critical thinking skills not only among its leaders but also among its members regardless of status and position. This is where the model of Community of Inquiry becomes relevant. The application of the principles of deliberative dialogue strengthens the logical thread in any professional gatherings transcending personal biases and convictions. By cultivating critical thinking among all members, it transforms the organization from a rigid hierarchical body to a vibrant and collaborative community where everyone takes responsibility in every step taken in inching towards the goals and objectives of the organization.

\section{References}

Al-Khatib, Jamal A., Mohammed, Y.A. Rawwas, \& Vitell, Scott J. (2004). Organizational ethics in developing countries: A comparative analysis. Journal of Business Ethics, 55(4), 309-322. Retrieved 8 August 2016, from http://www.jstor.org/stable/25123397

Brown, Andrew D., \& Starkey, Ken. (2000). Organizational identity and learning: A psychodynamic perspective. The Academy of Management Review, 25(1), 102-120. Retrieved 8 August 2016, from http://www.jstor.org/ stable/259265

Browne, Niel, \& Keeley, Stuart. (2007). Asking the right questions, a guide to critical thinking. New Jersey: Pearson Prentice Hall.

Chartrand, J., Ishikawa, H., \& Flanigan, S. (2013). Critical thinking means business: Learn to apply and develop the NEW \#1 workplace skill. Pearson Education. Retrieved 20 June 2016, from www.talentlens.com/en/downloads/ whitepapers/Pearson_TalentLens_Critical_Thinking_Means_Business.pdf

Ennis, Robert. (1991). Critical thinking: A streamlined conception. Teaching Philosophy, 14(1), 5-24.

Ferguson, Roger. (2011). Long-term financial security. In Rosenfeld, G., Lorsch, J. \& Khurana, R. (Eds), Challenges to business in the twenty-first century (pp. 3-7). Cambridge: American Academy of Arts and Sciences.

Gentry, William, \& Eckert, Regina H. (2016). The challenges leaders face around the world, more similar than different. Center for Creative Leadership. Retrieved 20 June 2016, from https://cclorg-wpengine.netdna-ssl. com/wp-content/uploads/2015/04/ChallengesLeadersFace.pdf

Glynn, Mary Ann., Barr, Pamela S., \& Dacin, M. Tina. (2000). Pluralism and the problem of variety. The Academy of Management Review, 25(4), 726-734. Retrieved 8 August 2016, from http://www.jstor.org/stable/259201

Kiggundu, Moses., Jørgensen, Jan J., \& Hafsi, Taieb. (1983). Administrative theory and practice in developing countries: A synthesis. Administrative Science Quarterly, 28(1), 66-84. Retrieved 8 August 2016, from http:// www.jstor.org/stable/2392387

Lipman, Matthew. (2003). Thinking in education. New York: Cambridge University Press.

Paul, Richard, \& Elder, Linda. (2006). Critical thinking. USA: Pearson Prentice Hall.

Ricci, Frederick (2014). Cultivating critical thinking within organizations. Proceedings of SOCIOINT14 - International Conference on Social Sciences and Humanities, 67-74.

Schmidt, Frank, \& Hunter, John. (1998). The validity and utility of selection methods in personnel psychology: Practical and theoretical implications of 85 years of research findings. The American Psychological Association, 124(2), 262-274.

Verbos, Amy Klemm., Gerard, Joseph A., Forshey, Paul R., Harding, Charles S., \& Miller, Janice S. (2007). The positive ethical organization: Enacting a living code of ethics and ethical organizational identity. Journal of Business Ethics, 76(1), Corporate Identity, Ethics and Corporate Social Responsibility, 17-33. Retrieved 8 August 2016, from http://www.jstor.org/stable/25075492

Voss, Zannie Giraud., Cable, Daniel M., \& Voss, Glenn B. (2006). Organizational identity and firm performance: What happens when leaders disagree about 'who we are'? Organization Science, 17(6), 741-755. Retrieved 8 August 2016, from http://www.jstor.org/stable/25146074

Whetten, David. (1984). Effective administrators. Change, 16(8), 38-43.

Whetten, David, \& Cameron, Kim. (2011). Developing management skills (8th ed.). New Jersey: Prentice Hall. 